\title{
KEY ASPECTS OF THE HISTORY OF THE \\ INFORMATION SYSTEMS DISCIPLINE IN AUSTRALIA
}

\author{
Roger Clarke \\ Xamax Consultancy Pty Ltd. \\ Canberra ACT Australia \\ Roger.Clarke@xamax.com.au
}

\begin{abstract}
The Information Systems discipline is 40 years old, in Australia, as in Scandinavia, the U.S.A., the U.K. and Germany. This paper presents what may be the first formally published attempt at a history of the discipline in this country. It identifies the precursors to the discipline, and its emergence in colleges and universities. It identifies institutions and individuals who were present at the birth, and traces key steps in organisational and political history. More controversially, it provides interpretations of the nature of the discipline and its key intellectual themes, and identifies threats to its survival.
\end{abstract}

\section{INTRODUCTION}

The natural starting-point for this Special Issue is a review of the origins and foundation years of the Information Systems (IS) discipline in Australia. Preparing such a paper is an undertaking that anyone would enter into only with considerable trepidation. There is a very limited literature on the history of the discipline as a whole, and almost nothing appears to have been published in formal outlets on the discipline in Australia. It is timely that an initial contribution be offered, because many of the early players have already reached retirement age and the rest are approaching it.

The author has been active in the discipline since 1968. The project was accordingly commenced by utilising the author's own archives and memory to construct a basic framework of times, places, people and topics. This had the advantage of resource efficiency, and of course the disadvantage that a personal perspective may have unduly limited the subsequent information-gathering steps.

The project continued with archival research. No formal histories of the discipline in Australia were identified, and few of the discipline elsewhere. The only formalised departmental histories that were unearthed were Greig \& Levin (1989) regarding Computing at Caulfield/Chisholm (196588) and Dreyfus (2004) regarding the University of Melbourne (1994-2004). Interviews were performed face-to-face, by telephone and by email with a selection of individuals who were known by the author to have long standing in the field, or were identified by early interviewees. 
A working paper was prepared and circulated within the project team and to further selected individuals who it was anticipated would be able to contribute further information and to identify errors, anomalies and omissions. The Acknowledgements section lists the individuals on whom I have placed greatest reliance.

This paper was developed by extracting key aspects from the revised working paper with the intention of providing a 'scene-setter' for the Issue as a whole. This paper is lightly referenced, with the intention that some of the trappings of scholarship be sacrificed in favour of readability. The underlying working paper addresses most aspects more fully, and provides further references. Access to the working paper and to collections of further resources is provided at the end of this paper.

The organisation of a paper of this nature could be approached in several ways. A chronological recitation would lack depth, and so too would a focus on Australia to the exclusion of the rest of the world. On the other hand, a purely thematic discussion would involve continual and confusing reversions in time. Accordingly, a blend of the chronological and the thematic has been adopted. This provides a counterpoint to the 'disciplinary developmental' approach adopted in Ridley (2006), elsewhere in this Special Issue.

The paper commences by identifying events and individuals that appear to have been key to the passage of the discipline from its embryonic state towards a mature community of scholars. That is followed by a brief discussion of the nature of the information systems discipline. A number of intellectual themes are then picked out that appear to have been the subject of heated, and in many cases recurrent, debate. A brief overview of the organisational settings in which the IS discipline has been practised precedes an examination of the political dimensions of the discipline - which in turn sets the scene for the evaluation of the current state of play that is undertaken by the papers in the body of this Special Issue.

Some caveats are important. The paper is sole-authored, rather than being the product of a substantial collaboration or task force. The author is not a professional historian. And, far from being a disinterested observer, the author was a participant and contributor throughout the period under review, and was and remains a protagonist in some of the debates. The invitation from the Editor of the Special Issue was for a paper that was brief rather than comprehensive. As a result of all of these factors, it is inevitable that the reader will detect selectivity of topics, mannerism in their treatment, and intrusion of the perspective of the individual or of 'schools of thought'. If the reader considers that the paper's deficiencies outweigh its contributions, they should regard this document as merely a first attempt, and a stimulant for their own efforts.

\section{FOUNDATIONS OF THE DISCIPLINE IN AUSTRALIA}

This section provides a rendition of the years prior to and following the establishment of the first departments of IS in Australia.

\section{Emergence - to 1965}

Some disciplines are blessed with a single name from the outset (e.g. history, engineering); others have a dominant title that migrates seamlessly at some point in time (e.g. philosophy of science to science and technology studies); and yet others have a primary name with variants (e.g. computer 
science). One major challenge that confronts someone studying IS is that the appellations applied to it have been highly varied both cross-sectionally and longitudinally.

Contrary to the predictions of 'cultural cringe' theory, the IS discipline in Australia did not follow on from developments overseas, but emerged in parallel with them. Not only did early patterns elsewhere not determine the directions of development of the discipline here, they did not even greatly influence them until the end of the 1970s. Nonetheless, it is convenient to commence by briefly outlining the beginnings of the discipline in key locations overseas.

Predecessor professional activities can be readily found in the design of manual and automated data processing systems through the first half of the twentieth century, but no academic discipline can be discerned during that period. Broad consensus exists that the primary stimulus for the emergence of IS was the administrative application of computers, commencing in 1951 with the Lyons Tea Company in the U.K. (Caminer et al. 1998, Land 2000), and Univac for the U.S. census (e.g. Johnson 2006).

Even then, there was a considerable gestation period. The foundation of the IS discipline is most conveniently identified as being in 1965, with the earliest contributions that can be unequivocally identified being those of Borje Langefors in Sweden and Gordon Davis and Bill King in the U.S.A., followed very shortly afterwards by Enid Mumford, Frank Land and Peter Keen in the U.K. and Dan Couger, Jim Emery and Warren Macfarlan in the U.S.A.

The major regions that contributed to its establishment and maturation have had substantially different flavours. Very roughly and inadequately, the driver of the discipline in the U.S.A. (where it has always been referred to as Management Information Systems - MIS) has been value to the organisation and management, and it has tended towards managerialism and managerial rationalism. Scandinavia and the U.K. have from the beginning had a much stronger association with human behaviour within organisations and hence with what might be termed 'constructive looseness'. In Germany (where it was and remains Wirtschaftsinformatik - WI, whose sense is approximately 'Business Applications of Computer Science'), there has been a sustained and strong orientation toward data processing and software development.

In Australia, an immediate predecessor to the discipline was the Commonwealth public sector's Programmer in Training (PIT) scheme, which ran primarily in Canberra, Sydney and Melbourne from 1963 to 1970. (Many Commonwealth agencies were located outside Canberra until the Whitlam era, 1972-75). About half of the PIT scheme's syllabus addressed systems analysis and design, and it produced hundreds of graduates who not only populated, and continue to populate, senior positions in the public sector nationwide, but also filtered out into leadership positions in the private sector.

\section{Establishment - 1965-1973}

Departments were established in Colleges of Advanced Education (CAEs), commencing in 1965, in order to assist in the application of computers to business and government. In some cases, the need was at the low level of fostering computer awareness and providing basic training in their use, and in others at the trade and professional levels of operating computers, and especially developing application software to run on them. Hence EDP and Software Development were early terms applied to clusters of IS staff. A few concentrations of IS staff emerged in accounting departments and were a little further removed from machines and a little more concerned with (particular kinds of) information. Until as late as 1990, a great deal of the time of many IS academics was committed 
to imparting basic computer-usage skills to students, most of whom were not otherwise enrolled in IS units.

The first specialist Department, called Electronic Data Processing (EDP), appears to have been established at Caulfield Institute of Technology in 1965. (During successive reorganisations, Caulfield was later re-named Chisholm, and finally absorbed into Monash University in 1987). The courses that it offered combined instruction about technology with teaching about how to apply it. Programming was a central feature, because all applications had to be custom-built.

The transfer of the PIT scheme into several CAEs at the beginning of the 1970s marked a key shift in education and training, as 'train your own' gave way to a formalised educational system. Departments were also established in the Institutes of Technology, QIT (now QUT), NSWIT (now UTS), RMIT, SAIT (now UniSA) and WAIT (now Curtin).

Meanwhile, IS topics emerged in university Accounting Departments. It appears that the first identifiable unit of study, in EDP, was established by Len Dunn in the Department of Economics \& Commerce at the University of Tasmania in 1965 (using Algol as a teaching vehicle). This was closely followed by UNSW and the University of Queensland c. 1966-68, and then Wollongong College of UNSW and the University of Melbourne in 1970. Sydney and Melbourne were major world cities, and Wollongong was one of the major centres in the then-very-large steel industry. Hobart's early activity was presumably stimulated by the large installation at the Tasmanian HydroElectric Commission. By the beginning of the 1970s, Honours theses in IS topics began to emerge from the UNSW and University of Queensland accounting departments.

It is instructive to compare the pattern of development in IS with the emergence of Computer Science (CS). Although CS units emerged from the late 1950s in departments of physics, electrical engineering, mathematics and statistics, the growth was very slow until the mid-to-late 1960s (i.e. at much the same time as IS). Offerings in computer science in most cases migrated from postgraduate diplomas back to final-year undergraduate, eventually expanding into full majors (which mirrors CAE offerings in EDP, whereas in most universities IS migrated forward from undergraduate service topics and units to sub-majors, majors and only later postgraduate teaching and research).

The first full Computer Science majors became available only in 1975, at the Universities of Melbourne and Tasmania. By this time, demand had ensured that many universities offered IS service units, IS majors had been launched at UNSW, Uni of Tasmania and QUT, and some of the CAEs had begun to offer full undergraduate awards to complement their postgraduate diploma courses. A critical difference between the two disciplines was that, by the end of 1973, there were at least 6 Professors of Computer Science, but none of IS. As CS gathered momentum, it had the opportunity to claim applications of computing as its own, which would have denied vital space to IS; but its leaders almost unanimously chose not to do so.

During these early years, most IS academics were loners, and they mostly presented their papers at conferences run by computer scientists (in particular the Australian Computer Conference series run from the early 1960s onwards) or by accountants. The Computing in CAEs conference series emerged as a focal point and ran c. 1970 to 1990, but there appears to be no formal archive of the papers presented at them. 


\section{Consolidation - 1974-1990}

In 1974, UNSW appointed the first Professor of IS, Cyril Brookes, and formed the first University IS Department, almost a decade after the CAE sector had started to form departments of computing and data processing. The first Masters dissertation appearsto have been completed in 1976 (by Roger Clarke), then in 1978 the first Australian was awarded a PhD in IS (Ron Weber at Minnesota, under Gordon Davis' supervision). The first PhDs awarded in IS in Australia were in 1982 and 1984 at the University of Queensland, supervised by Ron Weber (Errol Iselin and Iris Vessey) and in 1986 at UNSW, supervised by Cyril Brookes (Ross Jeffery).

Ron Weber was the second Professor, but his post was only partly in IS, and he did not take it up until 1981, by which time there were close to a dozen Professors of Computer Science. It was only in the immediate post-Dawkins era at the very end of the 1980s that additional full professorial positions were created, notably at Monash, which, when it absorbed Chisholm Institute of Technology, took over the mantle from QIT/QUT as the largest concentration of IS academics in Australia. The number of professorial posts surged during the 1990s, with about 20 created. By 2005, there were over 30 .

Until at least the mid-1980s, there was no clear body of knowledge for the IS discipline in Australia. The software development life cycle (SDLC) and database management had both emerged in the late 1960s. But it required years of experimentation and refinement before they matured and merged into structured analysis and design. Only then was a sufficiently comprehensive framework available for the management of software development projects. In addition, no prior student knowledge of technology could be assumed, so a considerable amount of time had to be spent on introductory computing topics.

Published curricula emerged early in the U.S.A. (the first being Couger 1973), and some time later in the U.K. Although informative, they were not well-fitted to the Australian context. They were comprehensive, and were oriented towards either computer science or the specifically U.S. form of graduate schools of business. Because limited time was available within IS service units, topics had to be selected, and integrated into local course environments. As a result, curriculum development in Australia was largely localised and in many cases insular. The first local text-book, Brookes et al., appeared only in 1982. A list of leading texts of the mid-1980s is in Clarke (1987).

The formation of the Australian Computer Society (ACS) in 1966 owed much to the efforts of academics in foundation disciplines such as mathematics and physics; but its primary role quickly became that of a professional association. Its most direct relationship with the IS discipline has been as an accreditation body, assessing the suitability of courses as a basis for professional Membership of the Society. Yet such was the dominance of computer science in the organisation, and such was the variability in the philosophies and curricula in IS courses, that it took until 1990 before IS was formally recognised within the Accreditation Guidelines (Clarke \& Lo 1989). The change was substantial, however, with the Core Body of Knowledge established by the ACS in 1992 (Maynard 1992, Underwood 1997) evidencing a 50-50 split between CS and IS topics.

Through the 1980s, the early emphasis on custom-built applications came to be complemented by the customisation and implementation of pre-written packages, and the orientation toward software development gradually gave way to a focus on systems integration. In parallel with that, the closed shop of large mainframe installations was gradually giving way to 'personal computers' and then to local area networks and client-server architecture. 
The orientation in Universities was most commonly away from programming and towards the analysis, design and implementation phases of development and integration, reflecting the realisation that relevant and effective information systems depended on fit with and embedment within human processes. There were parallel developments in IS management, in decision support, and later in the strategic management of IT and of information itself. Over time, information management became a distinguishable body of knowledge, and intellectual relationships developed with library science.

Through the late 1970s and the 1980s, the vigour of the discipline in the USA resulted in that country establishing leadership in, and for many years even outright dominance over, the IS discipline. Specialist journals began to appear, the first being MISQ and Database c. 1977, together with specialist conferences, particularly ICIS from 1980. During this period, IFIP TC8 (Technical Committee 8 of the International Federation for Information Processing), whose locus was primarily Europe, began to run conferences. Australians took advantage of these publishing and networking opportunities, and ran well-attended international conferences here, the first in 1984.

A period of active debate about philosophies and methods of research took place through the 1980s. The establishment of the Association for Information Systems (AIS) in 1994 was associated with the emergence of a genuinely international discipline. U.S. numbers and energy have dominated publishing output throughout, but recent years have seen somewhat more accommodation among the pluralism of world views. It might be an exaggeration to speak of tolerance; but widespread if somewhat grudging recognition has emerged that there are multiple flavours of the discipline, and that it is appropriate that there be many outlets for research. Some venues intentionally reflect a broad array of approaches, whereas others are more focussed in their orientations. Relatively few topic-areas and treatments are unable to find a refereed venue, although the half-dozen journals that are generally regarded as being at the top end of the discipline would be seen by many as being less open than others.

By the end of the 1980s, some stability had been achieved in the conception of what IS was about. In their submissions to a review of what the government styled the 'Computing Studies and Information Sciences Disciplines', the ACS and the Australian National University utilised a graphic which was prepared by this author and is reproduced at Exhibit 1 below, which sought to convey the scope of IS and its relationships with adjacent disciplines. It was also published as Attachment 5 of Maynard (1992). IS was depicted as occupying vital space between the technical and business disciplines, encompassing a range of applied and instrumentalist topics, and interacting closely with many other disciplines and sub-disciplines. 


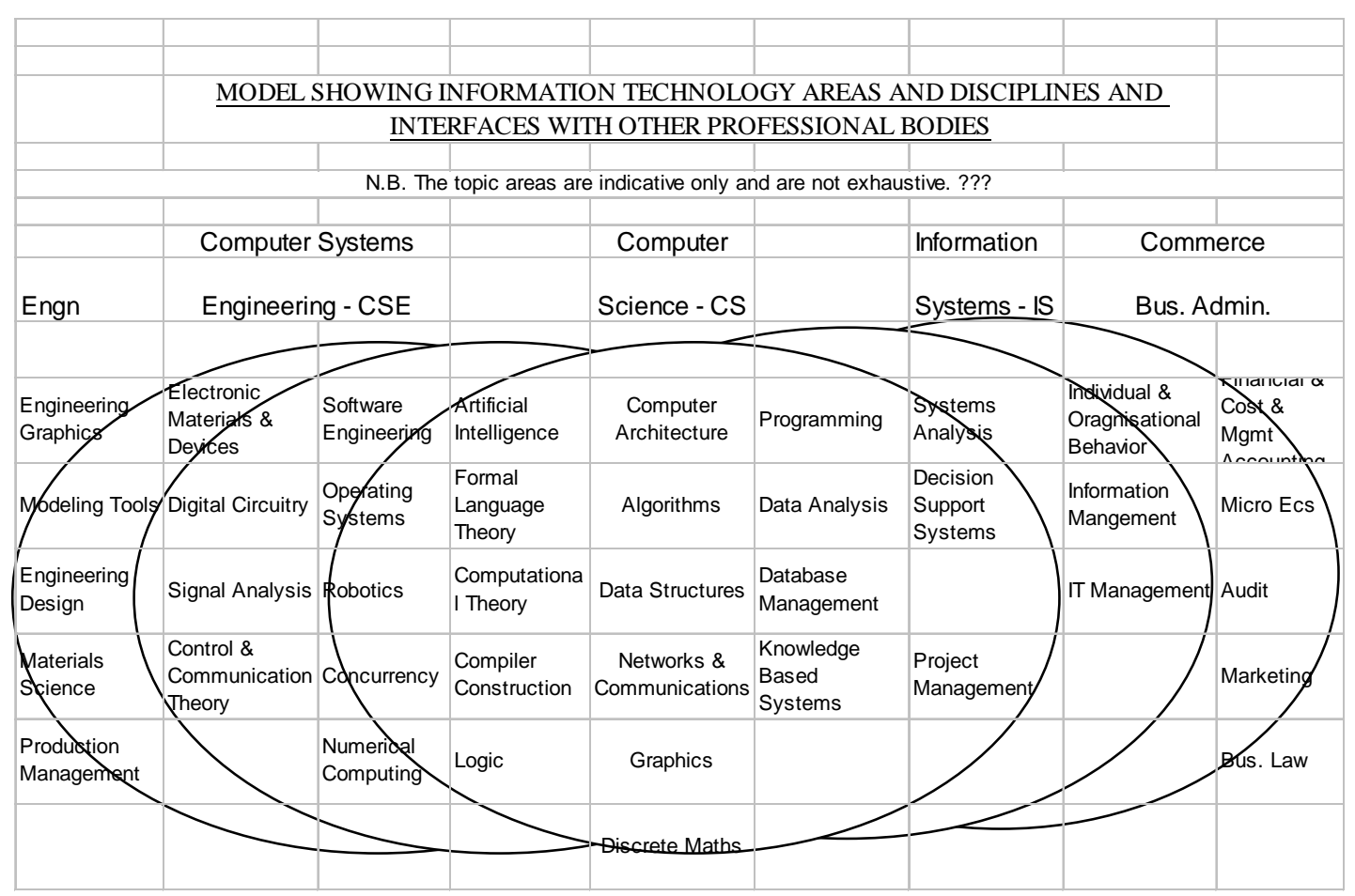

Exhibit 1: Location of the IS Discipline, as Perceived in 1991

THE NATURE OF THE DISCIPLINE

Most disciplines achieve a reasonable degree of unanimity about the nature and scope of their field, thereby marginalising 'deviant' thinkers, but leaving space for debate about what properly is and is not within-scope of the discipline. The definition of the IS discipline has been especially fraught. Rather than canvassing the array of possible definitions and getting caught up in nuance, this section briefly reviews the nature of the topics that the discipline involves.

One fundamental tension has existed throughout, and is reflected in the 'EDP in CAEs' and 'IS in universities' differentiation already noted in the previous section. At a gross level, two primary flavours of the IS discipline can be distinguished:

- a 'technology' flavour, which is tempered to a lesser or greater degree by business considerations; and

- a 'rational management' flavour, which views technology as a collection of interventions into organisational settings.

The technology that supports the handling of information was referred to as 'computing' until about 1980, and initially encompassed computers, their uses, and application software including its development, functionality and user interfaces. Subsequent to the marriage of computing with communications, it has been conventionally referred to as 'information technology (IT)' or 'information and communications technology (ICT)'.

The endeavour to provide intellectual under-pinnings for applications led early theorists to place 'information' and 'systems' at the heart of the discipline. The personal and psychological dimensions 
of perception and cognition attracted attention, but much more effort has always been focussed on the organisational contexts within which systems are used.

During the last few years, there has been a movement to focus on 'the IT artefact', a concept whose meaning continues to be debated, but that emphatically denies 'information' and 'system' as being at the heart of the discipline, and substitutes a technology-dependent idea.

A considerable amount of mechanistic thinking has entered the discipline, as teachers sought to simplify, reduce and automate. That has generated counter-movements imbued with interpretivist and critical perspectives, that are concerned with information-in-use and technology-in-use, and that deny that success can be achieved with simple formulae.

Ethics has made an appearance from time to time, but the discipline has paid very limited attention to the impacts and implications of the interventions that information systems and information technologies represent. Users of systems and technologies are most commonly regarded as agents of the corporations and government agencies that employ them, and seldom as principals or even participants. The notion of 'usees' - individuals affected by systems and technology, such as the people whose data is collected and managed - is barely detectable in IS teaching and research. Journal editors actively deny that there is any policy dimension to the discipline.

Building on this necessarily brisk depiction of the discipline's nature, the following section seeks out important themes during the discipline's life so far.

\section{INTELLECTUAL THEMES}

IS grew out of, and drew heavily from, a number of disciplines and schools of thought. Critical among them were Accounting and the applied end of Computer Science. Also of importance, in some departments more than others, were Organisation \& Methods (O\&M), Operations Management, Operations Research (OR) then Management Science (MS), Management Accounting, Management Theory, Business Strategy, General Systems Theory (GST) and Cybernetics, and Socio-Technical Systems.

IS researchers have for the most part avoided the creation of new theory, and have mostly drawn on theories that already existed in underlying disciplines, mostly in the social sciences. These are conventionally referred to as 'reference disciplines', although a critical observer would find it difficult to avoid using the term 'derivative' to describe a moderate proportion of the work in the discipline.

The approaches adopted were diverse from the outset, and no single text-book or school of thought dominated. The ideas of Langefors $(1963,1966)$, despite being translated into English at a very early stage, did not take strong root in Australia. Perhaps the single most influential book during the early years was Gordon Davis' 'Conceptual Foundations' (1974, 2nd edition as Davis \& Olson 1984). This provided a broad and liberal set of perspectives, and could be held up as an antidote to the more mechanistic and narrowly rationalist, often technology-driven, approaches. U.K. perspectives, particularly those in Mumford \& Banks (1967), Checkland (1981), Mumford (1983) and Wood-Harper et al. (1985), had considerable influence in some departments but little or none in others. 
Cataloguing the diversity of topics and approaches is a terrifying endeavour, but any discussion of a discipline's history simply cannot afford to overlook attempts at the encyclopaedist's approach. Early endeavours to define the scope included Mason \& Mitroff's (1973) 'program for research on MIS' and Ives et al.'s (1980) 'framework for research in computer-based MIS'. Local contributions included a 'manifesto for Australian-based research' (Galliers 1987), and a Special Issue on 'current research directions in IS' (Jeffery \& Lawrence 1990).

Reviews of the research undertaken in IS include Culnan (1986, 1987), Alavi et al. (1989), Alavi \& Carlson (1992), Avgerou et al. (1999), Galliers \& Whitley (2002) and Banker \& Kauffman (2004). Studies conducted in Australia include Galliers (1987), Ridley et al. (1998), Pervan \& CecezKecmanovic (2001), Pervan \& Shanks (2004) and Pervan \& Shanks (2006). These all attest to the enormous breadth of topics addressed within the IS discipline. The diversity arises in several dimensions:

- cross-sectionally, reflecting:

- the diversity of origins;

- the diversity of host disciplines and co-located disciplines; and

- longitudinally, as drift has occurred over time, driven by changes in technology, in fashion in management and in management disciplines, and increasingly in fashion within the IS discipline itself.

Barki et al. (1988, 1993) attempted to enumerate and provide structure to the topics that were within-scope of IS. Their proposed taxonomy of c. 2,000 terms was used for some years, but has since been abandoned because the rate of change is too high and no-one has the energy and authority to maintain it. Rather than adopting the Barki scheme, Exhibit 2 suggests a clustering of themes and topics in IS in Australia since 1965.

Exhibit 2 depicts a clustering, not a taxonomy. As is apparent from the appearance of such topics as adoption, systems analysis and project management in multiple clusters, there has been continual cross-feeding, and co-evolution of thinking.

The list of themes also evidences enormous diversity of research domains. These are viewed through the lenses of many theories, most of them imported, and imported from a wide variety of 'reference disciplines'. That the discipline's internal and external boundaries are so ill-defined and porous can be readily seen as an intellectual strength, because it implies adaptability and preparedness to focus on current needs. It can also be seen as an intellectual weakness, because it raises the question as to whether IS has the cohesion and substance required of a discipline. As will be discussed later, this also represents a political weakness.

Technology as Enabler and Driver, including computers, EDP, computer usage, applications development, the Software Development Life Cycle (SDLC), later the Systems Life-Cycle (SLC), systems design, systems analysis, project management, usability, technology adoption, technology acceptance, and impediments to adoption;

Applications of Technology, including accounting / FMIS / ERP, inventory / supply chain, management and executive applications (DSS, EIS, Business Intelligence and Knowledge Management), CRM, eCommerce, eBusiness, industry-sector-specific applications;

Data Management, including file-handling, Data Base Management Systems (DBMS), data modelling, data dictionaries, Entity/Attribute/Relationship (EAR) modelling;

Organisations, as the primary context within which information systems are developed and operated, and for whose purposes they are applied, including organisational behaviour, 
requirements elicitation and analysis, business process analysis, project management, change management, usability, technology adoption, and impediments to adoption;

Systems Thinking, including O\&M, GST and cybernetics leading from SDLC to SLC, sociotechnical theory, soft systems methods, incorporation of human factors, usability, adoption, and merging with human behaviour and communications into semiotics and perhaps ontological foundations;

Business School Thinking, including operations management, OR/MS, management accounting, controls and audit, project management, management of DP/IS/IT/ICT, strategic IS, information management, usability and adoption; and

Information Management, which grew in part out of library / information science, and delivered a vital appreciation of the role of metadata in enabling the discovery and management of information.

\section{Exhibit 2: Themes and Topics in Australian IS}

The diversity is as apparent in method as it is in research domain. The way to recognition and respect has been perceived by many academic leaders to be via commitment to methodological rigour. The natural byproduct has been harm to relevance, as researchers focus on the empirically researchable. An example of this is that electronic data interchange (EDI) has continued to be a focus in refereed publications in the eCommerce literature for years after it was rendered largely irrelevant by the explosion of the Internet. This was because EDI was stable and measurable, and hence could be subjected to more rigorous analysis than phenomena that were rapidly mutating. Whether and when the discipline will recover a healthier balance between rigour and relevance remains an open question.

Linked with that problem is the tendency to view the primary audience for the work by IS researchers as being one another. There is a dire risk of withdrawal to the 'ivory tower', and of becoming self-referential and self-serving. A healthy discipline of course involves active discourse among its members, but it also focuses on well-defined external constituencies. Serving those constituencies demands that much of the research not be 'pure', but be actively and willingly 'tainted' by applied notions (applying tools to problems) and by instrumentalist notions (tackling problems, and applying whatever tools appear likely to assist in the process). The IS discipline in Australia could be seen to have slid over the last four decades from an excess of pragmatic relevance to a dangerous obsession with purist rigour.

\section{ORGANISATIONAL SETTINGS}

It was noted above that early IS staff were loners. For many IS staff, that has continued to be the case, because, unlike most of the established disciplines, IS is frequently not a department in its own right. The most reliable information available (which is of at best moderate quality) is in the Directories of IS academics published in 1988-94 (Clarke 1988, 1991, Gable \& Clarke 1994, 1996), and integrated into the worldwide IS Directory when it was launched by ISWorld in 1995. Unfortunately, the data's quality since that time has dropped enormously, because no systematic follow-up has been undertaken. Nor has the potential for auto-updating from university web-sites been exploited.

By the end of the 1980s, almost all institutions had specialist organisational units focussed on IS. But the staff-count in those departments represented little more than half of the total, with many people out-posted in other departments. A significant difference from the patterns in the U.S.A. has 
been the relatively very limited involvement of and interest in IS by Australian Graduate Schools of Business, especially until the mid-1990s.

\begin{tabular}{|c|c|c|c|c|c|c|}
\hline Year & $\begin{array}{l}\text { Count of } \\
\text { Institutions }\end{array}$ & $\begin{array}{c}\text { Count of } \\
\text { Named IS } \\
\text { Depts }\end{array}$ & $\begin{array}{l}\text { Count of } \\
\text { Depts }\end{array}$ & $\begin{array}{c}\text { \%age of } \\
\text { Depts named } \\
\text { IS }\end{array}$ & $\begin{array}{l}\text { Count of } \\
\text { Individuals }\end{array}$ & $\begin{array}{l}\text { Count of } \\
\text { Professors }\end{array}$ \\
\hline 1988 & 41 & 9 & 55 & 16 & 175 & 2 \\
\hline 1991 & 39 & 22 & 76 & 29 & 521 & 7 \\
\hline 1994 & 38 & 32 & 84 & 38 & 640 & 13 \\
\hline 1996 & 39 & 39 & 88 & 44 & 630 & 15 \\
\hline 2005 & 42 & 28 & 103 & 28 & 692 & 30 \\
\hline
\end{tabular}

Exhibit 3: Institution and Staff Statistics

Exhibit 3 provides a statistical summary of the data in the Directory at various points in time. The growth surge apparent between 1988 and 1991 may be exaggerated by under-reporting in the first edition, but probably not greatly. Generally the data quality is likely to be highest in the figures for 1991, 1994 and 1996, which are based on project-managed surveys. No snapshot is available between 1996 and 2005. If one were, it would have been likely to show peak counts of individuals and professors, and possibly also of departments. The counts of individuals and professors in 2005 is under-stated because many new appointees have failed to create entries, but that is somewhat counter-balanced by the existence of undeleted entries for staff who have departed.

During the 1980s, IS staff with relevant doctorates were an aspiration for most departments, rather than a reality. There has been an increase in the number of degree-granting institutions, but many are not in a position to provide effective supervision for more than a small number of doctoral candidates, and few departments have articulated doctoral programs. Australian representation in international refereed conferences has been consistently strong since the late 1980s, but the increased professionalism is only slowly converting into impact in international journals. This can be attributed to strong competition arising from the ongoing high productivity of American scholars, the higher level of journal-publication productivity of European scholars in recent years, and the explosion in doctoral programs in other countries.

\section{POLITICAL DIMENSIONS}

From 1965 to c. 1990, communications within the discipline in Australia were informal and somewhat haphazard. An early step to draw the scattered individuals and groups together was the development of a Directory (Clarke 1988, 1991, Gable \& Clarke 1994, 1996). A critical initiative was the establishment of the national conference, the Australian Conference in Information Systems (ACIS). The first was held at Monash in 1989, and it has run annually since then. During the first few years, the standing committee comprised Ross Jeffery, Ron Weber, Roger Clarke, Peter Weill 
and Igor Hawryszkiewycz. The committee was then migrated to the ICIS pattern of rotating membership involving recent, current and near-future organisers.

The mid-1990s saw maturation of the IS discipline at the international level. As the Internet was grasped as an opportunity for international communications and publication, the ISWorld mailinglist and web-site were established, both in 1994. The international Association for Information Systems (AIS) was also formed in that year. The online worldwide directory consolidated the three regional printed directories in 1995. The regional fora PACIS (from 1993), ECIS (from 1993) and AMCIS (from 1995) emerged to provide a broader geographical frame for ACIS. Australians have been very active contributors to PACIS, ISWorld, the AIS and the Directory project, and to ECIS, IFIP TC8 and other international conferences.

Meanwhile, the national specialist journal the Australian Journal of Information Systems (AJIS) was established in 1994. Liaison among Professors and departmental heads had been emergent for some time, and was formalised through the Australian Committee of Professors and Heads of Information Systems (ACPHIS) in 1995. An ISWorld page for Australia was established by this author in 1996. Some years later, a chapter of AIS was established (AAIS, formed 2001).

Despite the gradual development of these cultural institutions, IS in Australia has remained marginalised, in many cases perceived as a mere service discipline, or as an interloper. For example, two 'sandstone universities' created departments only c. 1995 (Melbourne) and c. 2000 (Sydney), and Adelaide and U.W.A. have never had significant departments. The strongest employers were the 'red brick' universities, the Institutes of Technology, and specific Colleges of Advanced Education. In almost all cases, the big players had a strong orientation towards the technology flavour of the discipline, although some had sufficient critical mass to enable multiple perspectives to be nurtured, and to be reflected in coursework as well as research.

At the end of the 1980s, re-structuring of the tertiary education sector was forced by Labor Minister John Dawkins. The revolution was multi-pronged. It disestablished about 40 CAEs and 25 other smaller organisations and forced their amalgamation variously into the existing 19 Universities and 6 sometime Institutes of Technology, or into one of about 15 new combines (AVCC 2004). The changes destroyed the highly valuable distinction between institutions with industry-oriented mission statements and those with primarily academic orientation, resulting in wasteful confusion as CAEs struggled to become strong research-oriented institutions.

The success of the Commonwealth bureaucracy in imposing the changes gave rise to a culture of interventionism by the relevant agency, most recently the Department of Education, Science \& Training (DEST). Flurries of additional administrative responsibilities have been imposed on universities, drawing resources away from teaching and research. Per-student funding was slashed, and universities were forced to become entrepreneurial at short notice. The nominal objective of achieving administrative efficiencies was argued from the outset to be a mirage, and transpired to be just that. Lacking skills, and forced to learn them very quickly, many universities made ill-judged forays into crowded and difficult export markets, many suffered further financial damage as a result, and some teeter on bankruptcy. Managerialism rapidly replaced collegial structure and processes, and profit-making, or at least financial survival, dislodged all of the other objectives that universities had once had. Teaching standards plummeted under the assault of much-increased student/staff ratios, lower entry-points as institutions converted themselves into degree-factories for the upper half of matriculants, and huge increases in the numbers of fee-paying foreign students whose preparation and whose English were mostly below the intakes of earlier years, and in some cases well below. 
As a minor political player in an increasingly politicised environment, IS has suffered. The proportion of Departments containing IS that were named IS or similar grew steadily from the late 1980s to the mid-1990s to nearly half, but has plummeted since the end of the 1990s. Pearcey wrote nearly two decades ago (1988, p. 125) that "The demand for people with computing expertise has always outstripped the capacity of the tertiary sector to supply it, and the situation seems unlikely to change". Based on the author's experience, that was the case for at least three decades, from the late 1960s until the end of the 1990s.

About 2000, two factors conspired to cause dramatic change. Demand for IS graduates had become over-heated during the 'dot.com bubble' of the mid-to-late 1990s. Investors then made the remarkable discovery that most start-ups were presaged on establishing dominant market-share in a market that not only did not exist, but would not come into existence in time, if ever; and that hence almost all start-ups would fail. This resulted in a sudden loss of investor confidence, and the bubble burst. The other key factor was that offshore outsourcing had been progressively extending from data capture to programming and even detailed design work, reducing demand for local graduates.

The publicity accompanying this very large 'market correction' was followed by substantial reductions in enrolments from domestic students - although it appears to have had a smaller impact on foreign fee-paying numbers. A further factor in the disappearance of IS departments has been the external financial pressures on universities, which have encouraged the imposition of departmental amalgamations in the hope that this will result in cost-savings.

The 2005 staff head-count figures in Exhibit 3 are believed to reflect the position after the majority of the slashing had been undertaken. The timings of the down-sizing varied, but the quantum appears to have been mostly reasonably even across the country, with 20-30\% decreases the norm, although a small number were as high as $50 \%$. As is the way with 'the invisible hand' so beloved of economists, it appears very likely that the slump will have been an over-correction, and that there will soon be shortages in trained staff.

The damage done to the IS discipline following the 'dot.com bust' in 2000 is therefore in part understandable, and in part interim. In part, however, it reflects the discipline's ongoing political weakness. This meant that it was less able to gain control over the financial resources attributable to it during the boom times. Subsequently, during the recent downturn in student interest, it was less able to resist closures by demanding cross-subsidy, as has long been the norm among humanities and science disciplines that fall on hard times.

Further evidence of seriously inadequate political influence was the lack of formal recognition in the grants scheme (originally Australian Research Grants Council - ARGC, later Australian Research Council - ARC). The coding scheme has only included specifically IS terms since about 1998, and IS representation on the expert panel was only achieved in 2001.

It might have been feasible for the discipline to bolster its position within individual institutions and with government by drawing support from industry and government users. It has almost entirely failed to do so, however, because its links with employers of its graduates have always been tenuous and sporadic. Few departments have even created, let alone sustained, programs targeted at executives, and most employers avoid, and even deny, any responsibility to contribute to the preparation of the people they hire. Meanwhile, most professional development training continues to be product-specific and offered by suppliers, or somewhat more generic but offered by 
consultants. There is very limited linkage between on-campus postgraduate studies and employersponsored workplace training.

\section{CONCLUSIONS}

The IS discipline in Australia has grown from a standing start in 1965 to a body of c. 700 people, including c. 30 Professors, representation in every university, and a comprehensive set of cultural institutions. On the other hand, the discipline has always been characterised by porousness, derivativeness and unmanageable diversity, and has interleaved focus on discipline with a 'multidisciplinary' concern about research domains. These have translated into organisational fragmentation, ongoing self-doubt, and a lack of political power.

Is IS really a discipline? And does it matter if it isn't? Is there a core? Is it so heavily dependent on technology and management fashion that it can never have the stable core necessary for a recognised discipline? Is IS not a discipline, but merely a research domain that needs to be viewed through the lenses of a variety of genuine disciplines? Put more colourfully, are IS academics destined to wander forever, as Rosencrantz and Guildenstern to Hamlet, backstage bit-actors to host-discipline leads, under ongoing threat of irrelevance, and even execution? Has the value of the IS discipline been ephemeral? Does it need to be absorbed by broader disciplines either side of it? Does it need to continue to exist much as it does now, but with less energy wasted on existential angst? Or is existential angst simply a necessary rite of passage for a growing discipline?

During recent years, debate has raged about 'the core of the discipline', and the risk exists that there may be a reduction in scope from 'systems that handle information' to some notion of an 'IT artefact'. A further concern is that the IS discipline needs to extend its scope beyond exploratory, descriptive, explanatory and predictive outcomes to embrace the normative as well. Rather than ceding policy-relevant research to other, less timid disciplines, it is essential that IS declare needs associated with human values, and consider system features that assist in and that militate against the satisfaction of those needs. This would force maturation in the naïve notions of rigour and objectivity that have dominated the discipline in recent years.

This Special Issue is published soon after the 40th anniversary of the discipline in Australia, and as the generation of people active in the early years hand over the reins to succeeding generations. In a context as dynamic as that which afflicts IS it would be foolhardy to commit too much time to purely historical studies. On the other hand, careful study and consideration of the threads of history may provide the perspective needed in order to avoid further repetition of harmful errors.

The first four decades of the IS discipline in Australia saw progress and growth achieved, but in a context of multi-dimensional change, uncertainty and adversity. The next decade clearly promises more of the last three. Whether further progress and growth will be achieved, and even whether the discipline will survive in its present form, depends on the choices that today's leaders make about the discipline's scope, core, orientation, and attitude to the relevance-rigour balance. 


\section{REFERENCES}

Ackoff R.L. (1969) 'Management Misinformation Systems' Mngt. Sci. 14, 4 (December 1967) 147-156

Alavi M., Carlson P. \& Brooke G. (1989) 'The Ecology Of MIS Research: A Twenty Year Status Review' Proc. Int'l Conf. Infor. Syst., 1989, p. 198

Alavi M. \& Carlson P. (1992) 'A review of MIS research and disciplinary development' J. Mngt. Infor. Syst. 8, 4 (1992) 45-62

AVCC (2004) 'Australian Higher Education Institutions' Australian Vice-Chancellor's Association, 4 November 2004, at http://www.avcc.edu.au/documents/universities/AustralianHEMergesAmalgamations.pdf

Avgerou C., Siemer J. \& Bjorn-Andersen N. (1999) 'The Academic Field of Information Systems in Europe' Euro. J. Infor. Syst. 8 (1999) 136-153

Banville C. \& Landry M. (1989) 'Can the Field of MIS Be Disciplined?' Commun. ACM 32, 1 (January 1989) 48-60

Barki H., Rivard S. \& Talbot J. (1988) 'An Information Systems Keyword Classification Scheme' MIS Qtly 12, 2 (June 1988)

Barki H., Rivard S. \& Talbot J. (1993) 'A Keyword Classification Scheme for IS Research Literature: An Update' MIS Qtly 17, 2 (June 1993)

Benbasat I. \& Zmud R.W. (2003) 'The Identity Crisis Within The Is Discipline: Defining And Communicating The Discipline’s Core Properties' MIS Qtly 27, 2(June 2003) 183-194

Brookes C.H.P., Grouse P.J., Jeffery D.R. \& Lawrence M.J. (1982) 'Information Systems Design' Sydney, Prentice Hall, 1982

Caminer D., Aris J., Hermon P. \& Land F. (1998) 'LEO - The Incredible Story of the World's First Business Computer' McGraw Hill, New York

Checkland P. (1981) 'Systems Thinking, Systems Practice' Wiley, Chichester, 1981

Clarke R. (1987) 'The Computing Professional's Bookshelf' Austral. Comp. J. 19, 4 (December 1987) 222-223

Clarke R. (Ed.) (1988) 'Australian Information Systems Academics: 1988/89 Directory' Australian National University, November 1988

Clarke R. (Ed.) (1991) 'Australasian Information Systems Academics: 1991 Directory' Australian National University, April 1991

Clarke R. \& Lo B. (1989) 'Accreditation Requirements for Information Systems Courses for the Australian Computer Society' Australian Computer Society, November 1989

Couger J. (Ed.) (1973) 'Curriculum Recommendations for Undergraduate Programs in Information Systems' Commun. ACM 16, 12 (December 1973) 727-749

Culnan M. (1986) 'The intellectual development of management information systems, 1972-1982: a co-citation analysis' Mngt. Sci. 32, 2 (1986) 156-172 
Culnan M. (1987) 'Mapping the intellectual structure of MIS, 1980-1985: a co-citation analysis' MIS Qtly 11, 3 (September 1987) 341-353

Davis G.B. (1974) 'Management Information Systems: Conceptual Foundations, Structure, and Development' McGraw-Hill, 1974

Davis G.B. \& Olson M.H. (1984) 'Management information systems: conceptual foundations, structure, and development' 2nd ed., McGraw-Hill, 1984

Dearden J. (1972) 'MIS is a Mirage' Harv. Bus. Rev. January-February 1972, 90-99

Gable G. \& Clarke R. (Eds.) (1996) 'Asia Pacific Directory of Information Systems Researchers: 1996' National University of Singapore, 1996

Gable G. \& Clarke R. (Eds.) (1994) 'Asia Pacific Directory of Information Systems Researchers: 1994' National University of Singapore, 1994

Galliers R.D. (1987) 'Information Systems Planning: A Manifesto for Australian-based Research' Austral. Comp. J. 19, 2 (June 1987) 49-55

Galliers R.D. \& Whitley E.A. (2002) 'An Anatomy of European Information Systems Research ECIS 1993-ECIS 2002: Some Initial Findings' Proc. 10th Euro. Conf. Infor. Syst., Gdansk, Poland, June 2002

Ives B., Hamilton S. \& Davis G.B. (1980) 'A Framework for Research in Computer-Based Management Information-Systems' Management Science 26, 9 (September 1980) 910-934

Jeffery D.R. \& Lawrence M.J. (Eds.) (1990) 'Current Research Directions in Information Systems' Special Issue, Austral. Comp. J. 18, 4 (December 1986) 157-158

Johnson L.R. (2006) 'Coming to Grips with Univac' Annals of the History of Computing 28, 2 (April-June 2006) 32-42

Keen P.G.W. (1980) 'MIS Research: Reference Disciplines and a Cumulative Tradition' Proc. 1st Int'l Conf. Infor. Syst., Philadelphia, December 1980, 9-18

Keen P.G.W. (1991) 'Relevance and Rigor in Information Systems Research: Improving quality, confidence, cohesion and impact' , in Nissen H.E., Heinz K.L. \& Hirschheim R. (1991) pp. 27-49

Land F. (2000) 'The First Business Computer: A Case Study in User-Driven Innovation' J. Annals of the Hist. of Computing 22, 3 (July-September 2000) 16-26

Langefors, B. (1963). Some Approaches to the Theory of Information Systems, BIT, Bind 3, Hefte 4, 229-254

Langefors B. (1966) 'Theoretical Analysis of Information Systems' Lund, Sweden: Studentlitteratur, 1966

Lyttinen K. \& King J.L. (2004) 'Nothing At The Center?: Academic Legitimacy in the Information Systems Field' J. Assoc. Infor. Syst. 5, 6 (June 2004) 220-246

Mason R.O. (2005) 'Putting 'Systems' Back into Information Systems: An Essay in Honor of Gordon Davis' Working Paper, May 2005

Mason R.O. \& Mitroff I.I. (1973) 'A Program for Research on Management Information Systems' Management Science 19, 5 (January 1973) 
Maynard G.B. (1992) 'Report of the Task Force on the ACS Towards 2000' Australian Computer Society, 1992

Mumford E. \& Banks O. (1967) 'The Computer and the Clerk', Routledge Kegan Paul, 1967

Mumford E. (1983) 'Designing Human Systems', Manchester Bus. Sch., 1983

Nissen H.E., Heinz K.L. \& Hirschheim R. eds. (1991) 'Information Systems Research: Contemporary Approaches and Emergent Traditions' North-Holland, Amsterdam

Orlikowski W.J. \& Baroudi J.J. (1991) 'Studying Information Technology in Organizations: Research Approaches and Assumptions' Infor. Syst. Res. 2 (1991) 1-28

Orlikowski W. \& Iacono S. (2001) 'Desperately Seeking the 'IT' in IT Research - A Call to Theorizing the IT Artifact' Infor. Syst. Res. 12, 2 (June 2001) 121-134

Pervan G. \& Cecez-Kecmanovic D. (2001) 'The Status of Information Systems Research in Australia: Preliminary Results' Proc. 12th Austral. Conf. in Infor. Syst., December 2001

Pervan G. \& Shanks G. (2004) 'IS Research Activity in Australia: Results of the 2004 ACPHIS Research Survey' Presentation to Austral. Conf. Infor. Syst., December 2004

Pervan G. \& Shanks G. (2006) 'The 2005 Survey of Information Systems Research in Australia' Austral. Journ. of Infor. Syst., 2006

Ridley G. (2006) 'Characterising Information Systems in Australia: A Theoretical Framework' Austral. Journ. of Infor. Syst., 2006

Ridley G., Goulding P., Lowry G. \& Pervan G.P. (1998) 'The Australian Information Systems Research Community: An Analysis of Mainstream Publication Outlets' Austral. L. Infor. Syst. 5, 2 (1998) 69-80

Underwood A. (1997) 'The ACS Core Body of Knowledge for Information Technology Professionals' Australian Computer Society, 1997

Weber R. (2003) 'Still Desperately Seeking the IT Artifact' MIS Qtly 27, 2 (June 2003) iii-xi

Wood-Harper A.T., Antill L \& Avison D.E. (1985) 'Information Systems Definition: The Multiview Approach' Blackwell, Oxford, 1985.

\section{ACKNOWLEDGEMENTS}

Guy Gable provided the stimulus for this paper, and he, Bob Smyth and other members of the 'IS in Oz' project team provided important input to the work. The paper has benefited greatly from interviews with the following key players in IS, listed in alphabetical order: Cyril Brookes, Bill Caelli, Frank Land, Stewart Leech, Gerry Maynard, Graham Pervan, and Ron Weber. At least a dozen further senior members of the discipline made important contributions, including Dick Mason. Responsibility for the errors, the omissions, the unfortunate mis-phrasings, and the judgementally impregnated expressions, rests with the author. 


\section{APPENDIX}

The Working Paper from which this paper was developed is:

Clarke R. (2006) 'A Retrospective on the Information Systems Discipline in Australia' Xamax

Consultancy Pty Ltd, April 2006, at

http://www.anu.edu.au/people/Roger.Clarke/SOS/AISHist0605.html

The resources developed as part of the project are accessible at http://www.anu.edu.au/people/Roger.Clarke/SOS/AISHistApps0605.html.

They comprise:

1. Bibliography

1A: Historical and Reflective Articles on IS in Australia

1B: Early Articles on IS in Australia

1C: Curriculum-Related Publications

2. Resource Sites

2A. Resources - International

2B. Resources - Regional

2C. Resources - Australian - Publications

2D. Resources - Australian - Organisations

3. Timelines

3A. Timeline - International

3B. Timeline - Australian

4. Early Australian Professors in IS

5. Early Australian PhDs in IS

6. The International Impact of Australian IS

It is intended that the Working Paper and the resource-set be progressively corrected, refined and expanded, and archived in AJIS, AAIS and ACS repositories. Contributions should be sent to the author.

\section{THE AUTHOR}

Roger Clarke is Principal of Xamax Consultancy Pty Ltd, based in Canberra. He completed BComm (Hons I) and MComm degrees parttime at the University of New South Wales (UNSW) from 1967 to 1976, and taught IS there 1973-76 and in 1983. He was Reader in Information Systems at the Australian National University (ANU) from 1984 to 1995, during which time he was awarded a PhD by supplication.

He is a Visiting Professor in the Department of Computer Science at the ANU, in the E-Commerce Programme at the University of Hong Kong, and in the Cyberspace Law \& Policy Centre at UNSW. During the last 20 years, his primary interests have been in eBusiness, information

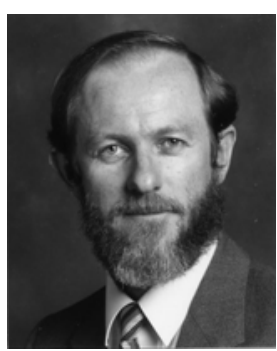
infrastructure, and dataveillance and privacy.

(C) Xamax Consultancy Pty Ltd, 2006 